\title{
Low prevalence of neisseria gonorrhoeae in owerri, Nigeria
}

\begin{abstract}
Gonorrhoeae is a purulent infection of the mucous membranes caused by the sexual transmission of the bacterium, Neisseria gonorrhoeae. It is a leading cause of pelvic inflammatory disease, which can result to complications such as tubal factor infertility, chronic pelvic pain, ectopic pregnancy and stillbirth. This study was designed to determine the prevalence of Neisseria gonorrhoeae Owerri, Imo State Nigeria; as well as the susceptibility of the recovered isolates to commonly used antibiotics for the treatment of the disease. The survey involved 49 consenting patients seen at St. John's Medical Laboratory Owerri who were presenting with signs and symptoms of sexually transmitted disease. Urethra swaps specimens were collected from male patients while highvaginal swabs and endocervical swabs were collected from female patients respectively. The specimens were processed and analyzed for Neisseria gonorrhea using conventional microbiological techniques of the 49 specimens analyzed, only $1(2.0 \%)$ urethra swap from a 38 years old man yielded Neisseria gonorrhoeae. Antibiotic susceptibility testing shows that the isolate was sensitive to ofloxacin, ciprofloxacin, azithromycin, and ceftriaxone but resistant to penicillin, tetracycline and doxycycline. Despite low rate of gonorrhea infection observed in this study, it is important to focus on high-risk populations (reproductive age group) because of the great physical and emotional costs of the disease. There is a need for a policy on routine screening for Neisseria gonorrhoeae since the treatment is available but the complications are dangerous to reproductive health.
\end{abstract}

Keywords: neisseria gonorrhoeae, low prevalence, Nigeria
Volume 4 Issue 2 - 2017

\author{
Chijioke A Nsofor, Jude Eletuoh \\ Department of Biotechnology, Federal University of Technology \\ Owerri, Nigeria
}

\begin{abstract}
Correspondence: Chijioke A Nsofor, Department of Biotechnology, Federal University of Technology Owerri, Nigeria, Tel +2348038783955, Email nsoforac@gmail.com
\end{abstract}

Received: January 14, 2017| Published: April 10, 2017

\section{Introduction}

Neisseria gonorrhoeae, the causative agent of the sexually transmitted disease, gonorrhea, is an obligate human pathogen that primarily infects the urogenital tract and cause male arthritis and female endocervicitis. ${ }^{1}$ The infection is transmitted from one person to another through vaginal, oral, or anal sex. Men have a $20 \%$ risk of getting the infection from a single act of vaginal intercourse with an infected woman; the risk for men that have sex with men is higher. Women have a $60-80 \%$ risk of getting the infection from a single act of vaginal intercourse with an infected man. A mother may also transmit gonorrhea to her newborn during childbirth, when affecting the infant's eyes, it is referred to as ophthalmic neonatorum. However, gonorrhea is not transmitted trough toilets or bathrooms. ${ }^{2}$ Half of women with gonorrhea are asymptomatic, whereas others have vaginal discharge, lower abdominal pain or pain with intercourse Most infected men have symptoms such as arthritis associated with burning sensation with urination and discharge from the penis. ${ }^{2}$ Either sex may also acquire gonorrhea of the throat from performing oral sex on an infected partner, usually a male partner. Such infection is asymptomatic in $90 \%$ of cases, and produces a sore throat in the remaining $10 \%$. With the advent of sulfonamide in 1936 and penicillin in 1943, antibiotic therapy for the treatment of gonococcal infection led to a rapid decrease in gonorrhea prevalence. Then since the beginning of the 20th century, peaks of reported cases of gonorrhea occurred during World Wars 1 and II and following the "sexual liberation" of the late 1960s and early 1970 s. $^{3}$ In the late 1980 s, with the onset of the HIV epidemic and a coincident widespread use of barrier contraceptives, the incidence of gonococcal infection again declined. ${ }^{4}$
In the absence of gonococcus screening program in the study area, little is known about the prevalence of gonococcal infection in Owerri, southeast Nigeria. To our knowledge, there is no data on the prevalence and antibiotics susceptibility pattern of Neisseria gonorrhea in the state. The STI surveillance system in the country is weak. This is because the pattern of reporting from health institutions is not uniform. Also drug resistance varies greatly among different regions. Therefore, having prevalence data as well as the drug susceptibility reties important especially for prevention and control of infectious disease such as gonorrhea. The major objective of this study was to assess the prevalence of Neisseria gonorrhoeae and their antimicrobial susceptibility patterns among symptomatic and asymptomatic individuals in Owerri southeast Nigeria.

\section{Material and methods}

\section{Sample collection, Isolation and Identification $\mathbf{N}$. gonorrhoeae}

Urethra swaps specimens were collected from male patients while high vaginal swabs and endocervical swabs specimens were collected from female patients respectively. The nature of the collected specimens was noted such as the colour, consistency and odour; the specimens were then examined under the low power (10x) and high power (40x) magnifications microscope for white blood cells, red blood cells, and epithelia cells. After the microscopic examinations, a presumptive diagnosis of $N$. gonorrhoeae was carried out using GC-Chocolate agar; the culture was incubated at $37^{\circ} \mathrm{C}$ in a humid, $10 \% \mathrm{CO}_{2}$-enriched atmosphere. Emergent colonies resembling $N$. gonorrhoeae, typical diplococcic in pairs, tetrads or clusters under the microscope were subjected to further biochemical confirmatory tests 
for identification $N$. gonorrhoeae. The following confirmatory tests were carried out according to the method of Cheesebrough. ${ }^{7}$ Catalase test, oxidase tests and colistin resistance test. All sampling procedures were in accordance with guidelines of the National Health Research Ethics Committee, Nigeria (www.nhrec.net).

\section{Antibiotic susceptibility testing}

Antibiotic susceptibility testing was carried out using KirbyBauer disk diffusion method on GC chocolate agar. From a pure culture of the isolate to be tested, a uniform streak was made on the agar plate. The antibiotic discs were then placed on the plates and incubated at $37^{\circ} \mathrm{C}$ overnight in a candle extinction jar enriched with $5 \% \mathrm{CO} 2$ in a moist atmosphere. Interpretation of results was done using the recommendation of Clinical Laboratory Standard Institutes. The isolate was tested for sensitivity to the following antibiotics: ciprofloxacin $(5 \mu \mathrm{g})$, doxycycline $(30 \mu \mathrm{g})$, erythromycin $(15 \mu \mathrm{g})$, penicillin $(10 \mu \mathrm{g})$, gentamycin $(10 \mu \mathrm{g})$ and tetracycline $(5 \mu \mathrm{g})$, ceftriaxone $(5 \mu \mathrm{g})$, ofloxacin $(5 \mu \mathrm{g})$.

\section{Results and discussion}

A total of 49 clinical specimens were analyzed for $N$. gonorrhoeae in this study, of which 7 were from consenting males with urethral discharge or dysuria and 41 were from consenting female patients with vaginal discharge. After the presumptive $N$. gonorrhoeae identification tests and microscopy, four isolates were suspected to be $N$. gonorrhoeae which involved three endocervical swabs specimens from the females and one urethra swab specimen from a male patient. On further laboratory analysis and conducting of confirmatory tests on the four presumptive positive isolates, only one $^{1}$ isolate was identified as $N$. gonorrhoeae and the specimen was that of the male patient from the presumptive tests. The antibiotic susceptibility tests result shows that, the $N$. gonorrhoeae isolate was sensitivity to ofloxacin, ciprofloxacin, azithromycin, ceftriaxone, gentamycin and spectinomycin, but was resistant to penicillin, tetracycline and doxycycline. In this study, the overall prevalence rate of $N$. gonorrhoeae among the study population was $2.0 \%$, with the isolated strain being sensitive to most of the antibiotics tested. This result is comparable to what has been earlier reported in different part of Nigeria and elsewhere; $1.4 \%$ among women in Lagos University Teaching Hospital, Lagos, Nigeria, ${ }^{5} 1.3 \%$ among pregnant women in Ilorin, Nigeria, ${ }^{6} 5.2 \%$ among pregnant women in Calabar, Nigeria, ${ }^{7}$ $3.2 \%$ in female patients attending clinics in the federal capital territory Abuja, Nigeria, ${ }^{8} 5 \%$ among undergraduate female students of University Of Port Harcourt, Nigeria ${ }^{9}$ and 5.1\%among symptomatic women in Hawassa Ethiopia. ${ }^{10}$ However, our data is considerably lower than the $16.3 \%$ observed in patients from different hospitals in Kaduna State Nigeria. ${ }^{11}$

The possible reason of the low prevalence of $N$. gonorrhoeae observe in this study could be due to the effectiveness of programs and campaigns against HIV/AIDS, unprotected sex and STDs in general. It can also be attributed to the age bracket of the study population, which included young people in the Owerri metropolis who are most likely to be students and enlightened individuals, and therefore must have taken advantage of condoms for their protection against STDs. Due to the isolation of only one $N$. gonorrhoeae strain in the study, the data was extremely insufficient to conclusively establish an antibiotic susceptibility pattern for $N$. gonorrhoeae in Owerri, although the isolate showed sensitivity to ofloxacin, ciprofloxacin, azithromycin, and ceftriaxone, gentamycin, spectinomycin and resistance to penicillin, tetracycline and doxycycline, we cannot make any categorical statement about the susceptibility rate of the pathogen in Owerri. Nevertheless, the high resistance observed in penicillin and tetracycline concurs with other studies, which shows that prevalence of penicillase producing $N$. gonorrheae in Nigeria has been on the increase since the first report by Bello in. ${ }^{12} \mathrm{~A}$ report by ObasekiEbor, Oyeide ${ }^{13}$ shows that with an initial prevalence rate of $12.5 \%$ in 1979 , the figure rose to $50 \%$ in 1981 at Ibadan and $87 \%$ in 1985 in Benin City. In 1986, a prevalence of $70 \%$ was recorded at Ilorin by Odugberni, Adetoro BA, ${ }^{14}$ also the prevalence rate of $83.3 \%$ in Jos was reported by Bello et al. ${ }^{15}$ while Bassyet al. ${ }^{16}$ reported $43.8 \%$ prevalence rate in FCT Abuja. Therefore, more surveillance is needed in Owerri to determine the actual rate of penicillase producing $N$. gonorrheae in the region.

\section{Conclusion}

We recommend that public health officials should continue their good work in creating adequate awareness aimed at curtailing the spread of $N$. gonorrheae /STDs in general. Also, specialized clinics for STDs should be established to ensure proper control and prevention of $N$. gonorrheae. (Table $1 \& 2$ ) representation showing the sex/sample type, age, gram staining, oxidase test, superoxol test, colistin resistance test for the positive presumptive, $N$. gonorrheae identification.

Table I Table showing the sex/sample type, age, microscopy and presumptive, N. gonorrhoeae identification

\begin{tabular}{|c|c|c|c|c|}
\hline $\mathbf{S} / \mathbf{N}$ & S/ST & Age & Microscopy & PNGI \\
\hline 1 & F/HVS & 36 & $W=I-3, R=$ nil, $E=+$ & \\
\hline 2 & F/HVS & 47 & $W=3-3, R=0-2, E=++$ & \\
\hline 3 & $\mathrm{~F} / \mathrm{HVS}$ & 41 & $W=0-2, R=2-4, E=+$ & \\
\hline 4 & M/US & 37 & $W=5-8, R=$ nil, $E=+$ & \\
\hline 5 & $\mathrm{~F} / \mathrm{HVS}$ & 33 & $W=1-3, R=5-7, E=+$ & \\
\hline 6 & $\mathrm{~F} / \mathrm{HVS}$ & 23 & $W=0-2, R=2-4, E=++$ & \\
\hline 7 & $\mathrm{~F} / \mathrm{HVS}$ & 34 & $W=10, R=5, E=+$ & \\
\hline 8 & $\mathrm{~F} / \mathrm{HVS}$ & 30 & $W=0-2, R=$ nil, $E=+$ & \\
\hline 9 & F/ECS & 31 & $W=4-6, R=7-9, E=+++$ & \\
\hline 10 & F/HVS & 25 & $W=0-2, R=0-2, E=+$ & \\
\hline 11 & M/US & 40 & $W=2-4, R=0-3, E=+$ & \\
\hline 12 & F/ECS & 27 & $W=7-9, R=3-5, E=+++$ & + \\
\hline 13 & $\mathrm{~F} / \mathrm{HVS}$ & 23 & $W=0-2, R=1-3, E=+$ & \\
\hline 14 & $\mathrm{~F} / \mathrm{HVS}$ & 24 & $W=0-2, R=0-2, E=++$ & \\
\hline 15 & M/US & 25 & $W=I-2, R=$ nil, $E=+$ & \\
\hline 16 & F/ECS & 28 & $W=8-10, R=2-4, E=+++$ & + \\
\hline 17 & $\mathrm{~F} / \mathrm{HVS}$ & 27 & $W=0-2, R=0-2, E=+$ & \\
\hline 18 & $\mathrm{~F} / \mathrm{HVS}$ & 29 & $W=I-3, R=3-5, E=++$ & \\
\hline 19 & $\mathrm{~F} / \mathrm{HVS}$ & 41 & $W=0-2, R=5-7, E=+$ & \\
\hline 20 & $\mathrm{~F} / \mathrm{HVS}$ & 35 & $W=2-4, R=3-5, E=++$ & \\
\hline 21 & $\mathrm{~F} / \mathrm{HVS}$ & 26 & $W=6-8, R=5-7, E=++$ & \\
\hline 22 & M/US & 29 & $W=2-5, R=$ nil, $E=+$ & \\
\hline 23 & $\mathrm{~F} / \mathrm{HVS}$ & 34 & $W=4-6, R=5-7, E=+$ & \\
\hline 24 & M/US & 29 & $W=4-7, R=1-2, E=+$ & \\
\hline
\end{tabular}


Table Continud....

\begin{tabular}{|c|c|c|c|c|}
\hline $\mathbf{S} / \mathbf{N}$ & S/ST & Age & Microscopy & PNGI \\
\hline 25 & F/HVS & 23 & $W=1-3, R=2-5, E=++$ & \\
\hline 26 & F/HVS & 34 & $W=3-5, R=$ nil, $E=++$ & \\
\hline 27 & F/HVS & 23 & $W=I-4, R=0-2, E=+$ & \\
\hline 28 & F/HVS & 33 & $W=0-2, R=2-4, E=++$ & \\
\hline 29 & F/HVS & 43 & $W=10-12, R=5-9, E=+++$ & \\
\hline 30 & F/HVS & 21 & $W=3-5, R=3-5, E=++$ & \\
\hline $\mathbf{S} / \mathbf{N}$ & $\mathbf{S} / \mathbf{S T}$ & Age & Microscopy & PNGI \\
\hline 31 & F/HVS & 22 & $W=1-3, R=1-3, E=+$ & \\
\hline 32 & F/HVS & 29 & $W=2-4, R=5-7, E=++$ & \\
\hline 33 & M/US & 38 & $W=16-19, R=1-3, E=+$ & + \\
\hline 34 & F/HVS & 25 & $W=1-3, R=0-2, E=+$ & \\
\hline 35 & F/HVS & 26 & $W=0-2, R=3-5, E=+$ & \\
\hline 36 & F/HVS & 29 & $W=0-2, R=$ nil, $E=+$ & \\
\hline 37 & F/HVS & 28 & $W=0-2, R=$ nil, $E=+$ & \\
\hline 38 & F/HVS & 27 & $W=1-3, R=2-5, E=++$ & \\
\hline 39 & F/HVS & 24 & $W=0-3, R=2-4, E=+$ & \\
\hline 40 & F/HVS & 25 & $W=I-3, R=3-5, E=++$ & \\
\hline 41 & F/HVS & 20 & $W=I-4, R=0-2, E=++$ & \\
\hline 42 & F/ECS & 44 & $W=10-13, R=3-5, E=+++$ & + \\
\hline 43 & F/HVS & 23 & $W=1-3, R=0-3, E=++$ & \\
\hline 44 & F/HVS & 20 & $W=0-2, R=3-5, E=++$ & \\
\hline 45 & F/HVS & 52 & $W=1-3, R=1-3, E=++$ & \\
\hline 46 & F/HVS & 23 & $W=6-8, R=3-5, E=++$ & \\
\hline 47 & F/HVS & 50 & $W=3-5, R=2-4, E=++$ & \\
\hline 48 & M/US & 30 & $W=3-5, R=$ nil, $E=+$ & \\
\hline 49 & F/ECS & 23 & $W=10, R=5, E=+++$ & \\
\hline
\end{tabular}

S/N, serial number; S/ST, sex/sample type; M/US, male/urethra swab; F/ECV, female/endocervical swab;WBC, white blood cells; RBC, red blood cells; EC, epithelia cells; PNGI, presumptive neisseria gonorrhoeae isolate; +, low presence; ++ , moderate presence; +++ , profuse presence

Table 2 Confirmatory test results

\begin{tabular}{lllllll}
\hline S/N & S/ST & Age & $\begin{array}{l}\text { Gram } \\
\text { stain }\end{array}$ & Oxidase & Superoxol & Colistin \\
\hline I & M/US & 38 & + & + & $4+$ & - \\
2 & F/ECV & 23 & + & - & - & - \\
3 & F/ECV & 28 & + & - & - & + \\
4 & F/ECV & 27 & + & - & - & + \\
\hline
\end{tabular}

S/N, serial number; S/ST, sex/sample type; M/US, male/urethra swab; F/ECV, female/endo cervical swab; Gram Stain, gram staining test; Oxidase, oxidase test; Superoxol, superoxol test; Colistin, colistin resistance test

\section{Acknowledgements}

None.

\section{Conflict of interest}

The author declares no conflict of interest.

\section{References}

1. WHO. Surveillance of antibiotic resistance in Neisseria gonorrhoeae in the WHO Western Pacific and South East Asian regions, 2007-2008. Commun Dis Intell Q Rep. 2010;34(1):1-7.

2. WHO. Global Prevalence and Incidence of Selected Curable Sexually Transmitted Infections: Overview and Estimates. 2005.

3. Knapp AS, Rice RJ. Neisseria and Branhamella. Principles and practice of infectious disease. 3rd ed. USA: Churchill Livingstone; 1995. p. 324 340 .

4. Aral SO, Holmes KK. Epidemiology of sexual behavior and sexually transmitted diseases. Sexually transmitted diseases. 3rd ed. USA: McGraw Hill; 1999. p. 39-76.

5. Onifade A, Osoba AO. Venereal diseases among Nigerian women attending intrauterine contraceptive device clinic. J Trop Med Hyg. $1996 ; 75: 213-216$.

6. Aboyeji AP, Nwabuisi C. Prevalence of sexually transmitted diseases among pregnant women in Ilorin, Nigeria. $J$ Obstet Gynaecol. 2003;23(6):637-639

7. Usanga VU, Abia-Bassey L, Inyang-etoh PC, et al. Prevalence Of Sexually Transmitted Diseases In Pregnant And Non-Pregnant Women In Calabar, Cross River State, Nigeria. Internet Journal of Gynecology \& Obstetrics. 2010;14(2):1-6.

8. Bassey BE, Kandakai-Olukemrz YT, Mawak D, et al. Prevalence of Neisseria gonorrhea in Female Patients Attending Clinics in the Federal Capital Territory (FCT) - Abuja, Nigeria. Nig J ExptI Appl BioI. 2000;1(1):1- 5 .

9. Wariso KT, Oboro IL. Prevalence of Neisseria Gonorrhoeae among Under Graduate Female Students of University Of Port Harcourt Using Strand Displacement and Amplification (Sda) Technique. IOSR Journal of Dental and Medical Sciences. 2013;7(4):76-79.

10. Hailemariam M, Abebe T, Mihret A, et al. Prevalence of Neisseria gonorrhea and their Antimicrobial Susceptibility Pattern Among Symptomatic Women Attending Gynecology Outpatients Hospitals in Hawassa Referral Hospital Hawassa, Ethiopia. Ethiop J Health Sci. 2013;23(1):10-18

11. Jatau ED, Galadima M, Odama LE, et al. Prevalence and antimicrobial susceptibility of Neisseria gonococcal isolated from patients in various locations of Kaduna state, Nigeria. Nigerian journal of surgical research. 2003;5(1):50-56

12. Bello CSS. Penicillinase producing Neisseria gonorrhea (pPNG). Report of first isolates in Northern Nigeria. W Afr 1 Med. 1982;1:39-40.

13. Obaseiki-Ebor EE, Oyaide SM, Okpere EE. Incidence of penicillinase producing Neisseria gonorrhea (pPNG) strains and susceptibility of gonococcal isolates to antibiotics in Benin City, Nigeria. Genitourin Med. 1985;61:367-370.

14. Odugbemi TO, Adetoro BA. Sexually transmitted diseases. A 19-month clinic experience at Ilorin University Teaching Hospital. Nig Med Pract. 1986;2:96-98

15. Bello CSS, Abdullahaman A, Tanyigna KB, et al. Relative prevalence of beta-lactamase producers among randomly selected bacterial pathogens isolated from clinical specimens in Jos over one year period. Nig Med Pract. 1996;31(5/6):83-85.

16. Chessbrough. District Laboratory Practice in Tropical Countries. UK Cambridge University Press; 2000. 464 p. 